metry and the absence of competition with nuclear resonance ${ }^{8,9}$. In 2-aminopyridine, where all Kekulétype resonance has been lost in one contributing form, the exaltation is vanishingly small. This diminution in resonance by loss of a benzene ring is seen again in the diminished exaltation of 7-aminoquinoline $\mathrm{V}$, as compared with its analogue, 2-aminoacridine. Finally, no extra ionic resonance is observed in 5-aminoquinoline (corresponding to practically none in 4-aminoacridine). This may well be because an ion derived from the imine $I V$, in addition to being orthoquinonoid (a structure that is relatively unstable and does not readily take part in ionic resonance ${ }^{10}$ ), must also lose both the Kekulé-type rings of quinoline.

An interesting by-path in these investigations has been the examination of our titration figures for 3-aminoquinoline in order to confirm the existence of the semi-hydrochloride that Mills and Watson ${ }^{11}$ postulated on the grounds of colorimetric and cryoscopic anomalies. However, the constancy of the $p \mathrm{~K}$ values obtained on adding one equivalent of hydrochloric acid to the base (Table 2) gives no indication of its formation.

While these simple aminoquinolines do not themselves possess marked chemotherapeutic properties, the main types of basicity discussed here will persist in their active derivatives. For example, pamaquin, a derivative of 8-aminoquinoline and the only aminoquinoline drug yet investigated, has a $p \mathrm{~K}_{a}$ of $3 \cdot 55^{12}$; similarly, in the acridine series the exaltation seen in 5 -aminoacridine persists in its derivatives 'Rivanol' and 'Atebrin'.

Because bases with $p \mathrm{~K}$ values below 6 are less than 10 per cent ionized at $p \mathrm{H} \mathrm{7,} \mathrm{while} \mathrm{those} \mathrm{with}$ values above 8 are practically completely ionized, a biologically important difference exists between drugs based on different aminoquinolines, and this should not be overlooked in interpreting the action of known drugs and in devising new ones.

${ }^{1}$ Maghidson, O., and Rubstov, M., J. Gen. Chem. Russia, '7, 1896 (1937).

${ }^{2}$ Galperin, E., Med. Parasitol. and Parasitic Diseases, Moscow, 9, 44 (1940)

${ }^{3}$ Iensch, H., Angew. Chem., 50, 891 (1937).

- Schönhöfer, F., Z. physiol. Chem., 271, 1 (1942).

${ }^{5}$ Mizutani, M., $Z$. physikal. Chem., 118, 327 (1925)

- Albert, A., Rubbo, S., and Goldacre, R., NATURE, 147, 332 (1941).

'Albert, A., and Goldacre, R., J. Chem. Soc., 454 (1943).

* Schwarzenbach, G., and Lutz, K., Helv. Chem. Acta, 23, 1162 (1940).

"Branch, G., and Calvin, M., "The Theory of Organic Chemistry" (Prentice-Hall, 1941), 194.

10 Sidgwick, N., "The Organic Chemistry of Nitrogen" (Oxford, 1937). 84, 441.

${ }^{11}$ Mills, W., and Watson, W., J. Chem. Soc., 741 (1910).

${ }_{12}$ Christophers, S. R., Ann. Trop. Med. Parasit., 34, 1 (1937).

\section{EARTH-FAULT RELAY EQUIPMENT}

\begin{abstract}
A PAPER entitled "A Modern Earth-Fault Relay A Equipment for use on Systems Protected by Petersen Coils" was read in London recently by L. B. S. Golds and C. L. Lipman before the Institution of Electrical Engineers, and in it the authors dealt with the automatic isolation or indication of earthfaults on such systems. After discussing the operating principle of this type of protection, describing the working of a wattmeter-type relay, and enumerating the electrical constants of the type of system to which the protection is applied, the paper describes the application of the relay to an actual $66-\mathrm{kV}$. system.
\end{abstract}

The currents in the feeders are analysed and the problem of accurate current summation is discussed in detail. A comparison is made between current summation by means of a summation transformer and by direct paralleling. Results are given of laboratory tests on current-transformers at currents approximating to the system capacitance currents. Further test figures are given showing the effect of load current in addition to capacitance currents. The design of the relay element, its constructional features and operating characteristics are described.

From experience gained on tests with artificial faults and under actual system earth-fault conditions, the relays were found to be quite reliable in operation, providing the equipment was connected correctly and the current-transformers were sufficiently accurate. When commissioning the gear, an artificial fault is valuable in proving the reliability of the equipment. By observing the operation of the relays at each substation with faults at selected points, the complete scheme can be put into operation with a minimum of testing. Preliminary tests are carried out by singleand three-phase injection to ensure that the transformers are balanced and that they comply with the specification.

These relays are being used in conjunction with phase-fault relays to switch-out one faulty line in the event of a double earth-fault, leaving the original fault on the system. The difficulty of extreme sensitivity has been overcome by the use of a resistance in series with the coil, which serves the double purpose of limiting the asymmetric current under healthy conditions and increasing the active component under fault conditions; this has the advantage of making the relay more robust.

\section{FORTHCOMING EVENTS}

\section{Monday, April 17}

INSTITUTION OF ELECTRICAL ENGINEERS (CAMBRIDGE AND DISTRICT WIRELESS GROUP) (at the Technical School, Cambridge), at 5.30 p.m. Televi. B. J. Edwards: "A Survey of the Problems of Post-War Television".

\section{Tuesday, April 18}

RoYAL ANTHRopologrcal INstituTe (at 21 Bedford Square, London, W.C.1), at 1.30 p.m.-Mr. Hans E. Adler: "Life in Soviet Turkestan".

BRITISH SOCIETY FOR INTERNATIONAL BIBLIOGRAPHY (at the Science Museum, Exhibition Road, South Kensington, London, S.W.7), at 4.30 p.m. -Mr. H. Thomas: "Co-operative Cataloguing"; Colonel Luxmoore Newcombe: "The Library of Congress Depository Catalogue and Bibliographical Service at the National Central Library". EUGENICS SocIETY (at the Royal Society, Burlington House,
Piccadilly, London, W.1), at 5 p.m.-Mr. D. Caradog Jones: "The Standard of Living".

ILLUMINATING ENGINEering Societr (joint meeting with the SCIENCE MASTERS' ASSOCIATION) (in the Large Physics Lecture Theatre, Imperial college of Science, Imperial Institute Road, South Kensington, London, S. W.7), at 5 p.m. Following a short introductory Address a series of Experiments illustrating the Production and Nature of Light, Photometry, the Fundamental Principles of be demonstrated and discussed.

INSTITUTION OF ELECTRICAL ENGINEERS (WIRELESS SECTION) (at Savoy Place, Victoria Embankment, London, W.C.2), at 5.30 p.m.Discussion on "Metals and their Finishes in Radio Construction" (to be opened by Dr. G. L. Sutherland).

ROYAL PHOTOGRAPHIC SOCIETY (SCIEN'TIFIC AND TECHNICAL GROUP) (at 16 Princes Gate, South Kensington, London, S.W.7), at 6 p.m.Mr. Y. A. C. Yule : "Unsharp Masks, a New Method of Increasing Deflnition in Prints".

Wednesday, April 19

SOCIETY OF CheMICAL INDUSTRY (joint meeting of the MicRoBIOLOGICAL PANEL OF THE FOOD GROOP, THE AGRICUITURE GROUP AND THE ASSOCIATION OF APPLIED BIOLOGISTS) (at the Chemical Society, Burlington House, Piccadilly, London, w.1), at 11 a.m.Society, Burlington House, Piccadilly, London, w.1), at 11 a.m.--
Papers on "Soil Sterilization". (Dr. W. F. Bewley " "Some Problems Papers on "Soil Sterilization". (Dr. W. F. Bewley " "Some Problems
in Soil Sterilization"; Mr. W. J. C. Lawrence: "Soil Sterilization in Soil Sterilization", Mr. W. J. C. Lawrence : "Soil Sterilization and Seedling Growth"; Mr. A. H. Dodd: "Considerations in F.R.S.: "A New Technique for the Study of Soil Sterilization" (with Demonstration); Mr. H. Lees and Dr. J. H. Quastel, F.R.S. "Effects of Chlorate Administration on Soil Nitrification"). 